\title{
2017 CMP Honoree: Professor Shirley Lindenbaum
}

\author{
Atwood D. Gaines ${ }^{1}$
}

Published online: 13 October 2017

(C) Springer Science+Business Media, LLC 2017

\section{CMP Honoree: Professor Shirley Lindenbaum}

In this, the last number of the 41st of Culture, Medicine and Psychiatry in 2017, we honor Anthropologist, Professor Shirley Lindenbaum. Professor Lindenbaum is well-known for her work on Kuru, Cannibalism, Nutrition, Gender and what we at CMP refer to as the Cultural Studies of Science and Medicine (outside of Medical Anthropology, the broader field is called STS-Science and Technology Studies or SSS-Social Studies of Science, and a number of other designations). Professor Lindenbaum is Professor Emerita in the Graduate Program in Anthropology at the City University of New York. She retired in 2009 and resides in New York City and remains active.

Professor Lindenbaum has worked long and hard on issues concerning the Fore and on prion diseases, notably Kuru, as well as AIDS and other health topics. Indeed, her work is a significant part of the reason we now know of prion diseases. She has also insightful critiques and cultural analyses of biomedical and biometrical, i.e., epidemiological, thinking and practices.

Previous Honorees of CMP include the inaugural honoree, anthropologist Dr. Margaret Lock, followed by medical sociologist Renée Fox, and psychological/ psychiatric anthropologists Robert Edgerton, Robert LeVine and Arthur Kleinman.

Atwood D. Gaines

atwood.gaines@case.edu

1 Case Western Reserve University, Cleveland, OH, USA 


\section{CMP Honoree: Professor Byron J. Good}

For 2018, CMP is pleased to honor Dr. Byron J. Good, the recent recipient of the Lifetime Achievement Award from the Society for Psychological Anthropology (SPA). We will make note of that honor in each number of the volume year; and, as per our practice, we will conclude the volume year (in number four) with an essay covering his academic career and a bibliography of his publications that will serve useful for readers wishing to explore the breadth and depth of his work. 